\title{
Heat Loss for a Run-Around Hybrid Ventilation System with Heat Recovery
}

\author{
Henrik Davidsson ${ }^{1}$ and Ricardo Bernardo ${ }^{1}$ \\ ${ }^{1}$ Lund University, Lund (Sweden)
}

\begin{abstract}
The heat recovery system for ventilation is of major importance when low energy buildings are built. One alternative to the mechanical ventilation systems with heat recovery is to use a brine based run-around system that allows for heat recovery in for instance hybrid ventilated buildings. This type of heat recovery system has the potential to lower the need for electricity for the fans. Also, the installation has the potential to be simpler when pipes transporting the brine replace traditional air ducts. However, pipes needed to transport the brine will suffer from thermal losses. This will lower the efficiency of the heat recovery system. High losses could in practice make the system unusable. In order to estimate how much this affects the annual heat recovery a simulation tool was developed using TRNSYS. The result from the investigation shows that the losses for a system with $40 \mathrm{~m}$ pipes in total are approximately $300 \mathrm{kWh}$ annually. This corresponds to approximately $9 \%$ of the energy savings from the ventilation heat recovery system. Insulating the pipes can reduce this heat loss by approximately $250 \mathrm{kWh}$ annually.
\end{abstract}

Keywords: Hybrid ventilation, Heat recovery,

\section{Introduction}

One advantage with using hybrid ventilation is the reduced need for electricity consumed by the fans in a conventional mechanical ventilation heat recovery system. The importance for this becomes apparent when considering the following example: A typical single-family house in Sweden consumes approximately 4000 $\mathrm{kWh}$ to heat the incoming ventilation air. If a mechanical ventilation system with $75 \%$ heat recovery rate is used it means that $3000 \mathrm{kWh}$ is saved on an annual basis. However, if we include the $456 \mathrm{kWh}$ of electricity Swedish Energy Agency (2010) which corresponds to about $1370 \mathrm{kWh}$ of primary energy (energy factor 3), the annual recovery rate is reduced to about $40 \%$.

One alternative to this is to use natural or hybrid ventilation. However, hybrid ventilation systems normally lack the possibility to recover any of the energy that disappears with the outgoing ventilation air. This will lead to high energy consumption for heating and it could also result in a poor comfort in cold climates due to cold draught from the incoming ventilation air. One possibility could be to install hybrid ventilation systems with heat recovery. Recent development concerning heat exchangers with very low pressure drop has made these types of systems possible, Hviid and Svendsen (2011), and Davidsson et al. (2013a). These types of heat exchangers can be used in run-around heat recovery systems, Davidsson et al. (2013b). A typical run-around system equipped with a heat recovery system is shown in Fig. 1. The incoming air is heat exchanged in the water/air heat exchanger at the bottom of the building. The brine is then pumped to the top of the building where it is used to recover heat from the outgoing ventilation air. The heat is pumped to the bottom of the building and the circle is completed. The temperatures in the figure are used as an example to illustrate the heat recovery process.

However, in this type of system there will be losses from the indoor air to the brine. This means that heat will flow from the indoor air to the brine. In the end this means that the heat recovery rate for the system will be reduced. There are three effects that should be kept in mind regarding this heat loss: 
1. Heat will be lost from the room to the brine.

2. The increased brine temperature will reduce the heat transfer rate in the heat exchanger at the top of the house from the air to the brine.

3. The increased brine temperature will increase the heat transfer in the heat exchanger at the bottom of the house from the brine to the air.

This rather complex behavior makes it more difficult to estimate the heat loss effect from the system over a full year. Further complication arises when a full building is included in the energy system and therefore a dynamic simulation model is needed to quantify the above listed behavior.

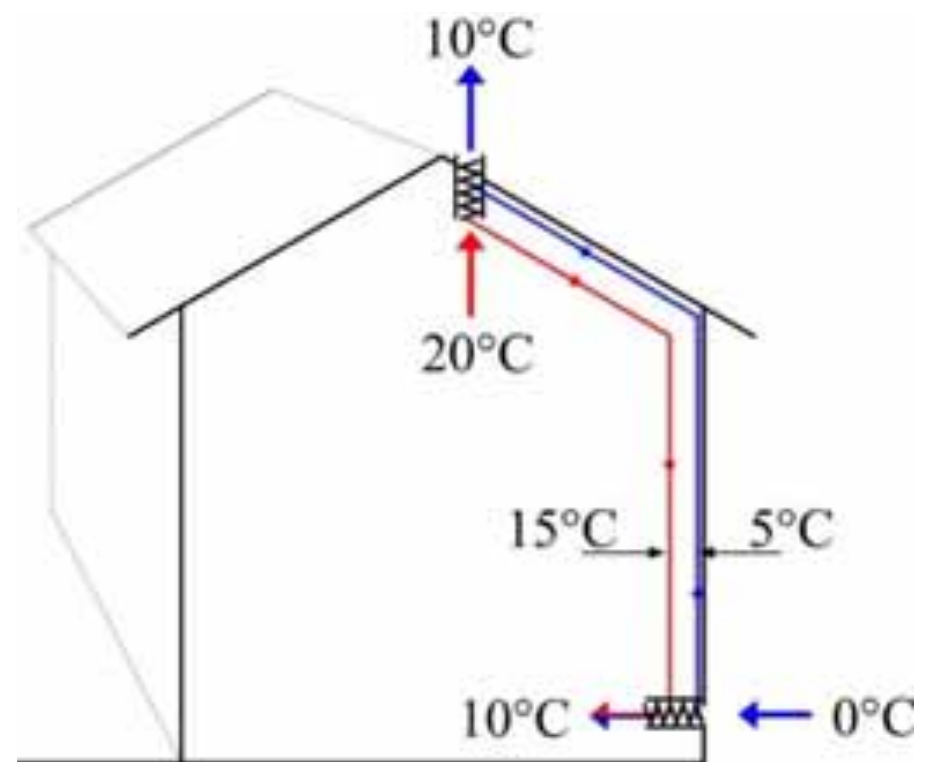

Fig. 1: Run-around heat recovery system suitable for hybrid ventilation.

\section{Method}

In order to investigate the consequences of heat losses in the pipes a TRNSYS simulation model was developed. The simulations do not include effects from dirt on the heat exchangers or air leakage. Nor does it include uneven consumption of electricity in the building or cooling during hours with overheating. The included TRNSYS components and the most important parameters are described in Table 1. The internal gains, window gains and thermal losses for the building are all included in the simulation in order to give a realistic surrounding for the ventilation system.

Tab. 1: Parameters and TRNSYS types used in the simulation tool.

\begin{tabular}{|c|c|}
\hline Building, TRNSYS type 88 & $\begin{array}{c}\text { The building has an average U-value of } 0.5 \mathrm{~W} / \mathrm{m}^{2} \mathrm{~K} \text {. The thermal } \\
\text { capacitance of the buildings was set to } 40 \mathrm{MJ} / \mathrm{K} \text {. This corresponds to } \\
\text { approximately } 100 \mathrm{~m}^{2} \text { concrete floor, } 100 \mathrm{~m}^{2} \text { brick wall and it includes } \\
\text { interior material and the roof. }\end{array}$ \\
\hline Internal gains & $\begin{array}{c}\text { Windows facing south }\left(6.5 \mathrm{~m}^{2} \text { glazing area), west }\left(6.5 \mathrm{~m}^{2}\right), \text { north }\left(4 \mathrm{~m}^{2}\right)\right. \\
\text { and east }\left(4 \mathrm{~m}^{2}\right) \text { with a g-value of } 55 \% \text { were installed in the building. This } \\
\text { gives a glazing to floor area ratio of approximately } 14 \% \text {, which is a } \\
\text { typical value. The transmitted solar radiation was treated as internal } \\
\text { gains of the building. The gain from people and electricity was set to } 500 \\
\text { W continuously. }\end{array}$ \\
\hline Weather data & $\begin{array}{c}\text { The weather data is data from Malmoe in the south of Sweden. The } \\
\text { weather data was obtained from Meteonorm (Meteonorm). }\end{array}$ \\
\hline
\end{tabular}




\begin{tabular}{|c|c|}
\hline $\begin{array}{c}\text { Ventilation: Heat } \\
\text { exchangers, TRNSYS type } \\
5 \mathrm{~b}\end{array}$ & $\begin{array}{c}\text { The ventilation flow rate for all cases was set to } 234 \mathrm{~kg} / \mathrm{h} \text { which is } \\
\text { approximately equal to an air change rate of } 0.5 \text { changes per hour. This } \\
\text { value was chosen in order to meet the requirements in the Swedish } \\
\text { Building code BBR (2011). The brine in the ventilation circuit was } \\
\text { assumed to be water. The temperature efficiency was set to } 75 \% .\end{array}$ \\
\hline Pipes: type 31 & $\begin{array}{c}\text { The pipes for the run-around ventilation system were assumed to have an } \\
\text { inner diameter of } 12 \mathrm{~mm} \text { and a total length of } 20 \text { meter for both flow } \\
\text { directions, i.e. to the roof heat exchanger and to the bottom heat } \\
\text { exchanger. The heat loss coefficient for the uninsulated and the insulated } \\
\text { pipes are given in Table } 2 .\end{array}$ \\
\hline
\end{tabular}

The heat resistance and thus the U-value of the pipes, uninsulated and insulated, where calculated using the program IsoDim from Isover (IsoDim). The values used in the different simulations can be seen in Table 2 . The calculated values only includes the pipes. Connections and diverters are not included.

Tab. 2: Heat transfer rate for pipes with various insulation thickness.

\begin{tabular}{|c|c|}
\hline Insulation thickness $/ \mathrm{mm}$ & U-value $/\left(\mathrm{W} / \mathrm{m}^{2} \mathrm{~K}\right)$ \\
\hline 0 & 7.7 \\
\hline 20 & 0.68 \\
\hline 40 & 0.31 \\
\hline 60 & 0.19 \\
\hline 80 & 0.13 \\
\hline 100 & 0.10 \\
\hline
\end{tabular}

\section{Result}

This building was calculated to use $15000 \mathrm{kWh}$ annually for space heating and heat for the ventilation. If the building is equipped with a heat recovery system, shown in Fig. 1, for the ventilation air the annual heating need is reduced to $11350 \mathrm{kWh}$ per year. This assumes a temperature heat recovery efficiency of $75 \%$. However, this simulation does not include any heat losses to the water piping system. If this is included the heating need is increased to $11660 \mathrm{kWh}$ annually. This assumes a total piping length of $2 \cdot 20$ meters with heat loss rate for the water pipes assumed to be $7.7 \mathrm{~W} /\left(\mathrm{m}^{2} \cdot \mathrm{K}\right)$. The effects of insulating the pipes are shown in Fig. 2 and Fig 3. The first of the two figures shows the annual heating for buildings equipped with a run around ventilation system with heat recovery. The results show that not including any losses in the calculations for the ventilation system will result in an overestimate of its performance by approximately $300 \mathrm{kWh}$ annually. However, insulating the pipes heavily will reduce this effect considerably resulting in only 50-100 kWh losses annually.

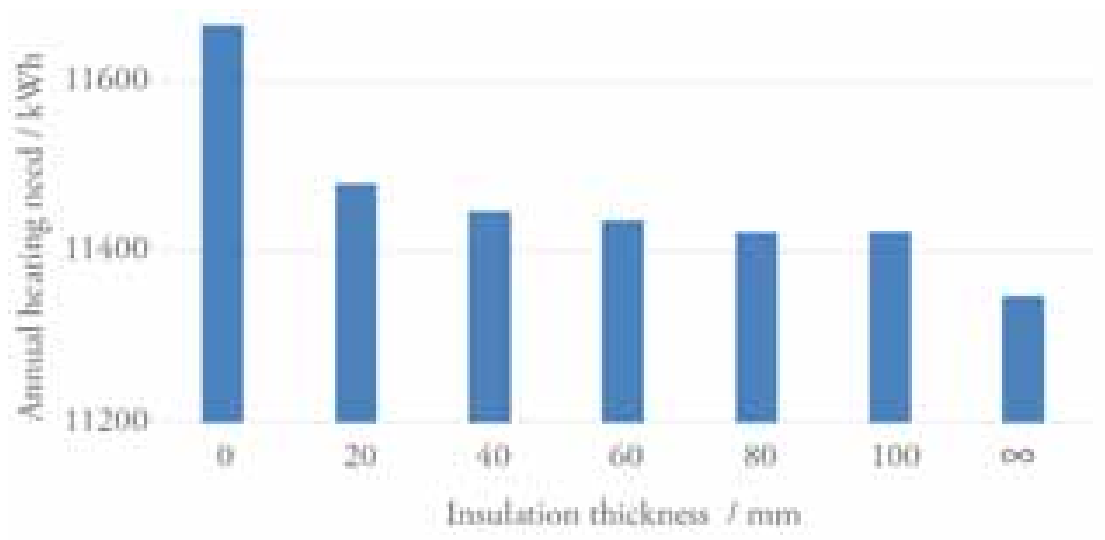

Fig. 2: The annual heating need for buildings with ventilation systems with different pipe insulation. Note the broken y-axis. 
Fig 3 shows with red bars that the heat transfer in the Bottom HX increases as the losses are included. This happens since the air inside the building will heat the brine going to the Bottom HX. This is not beneficial for the total energy performance for the building since the heat comes from the building itself. At the same time the energy transferred in the roof HX will decrease. This is shown with blue bars. This happens since the brine is already heated and less energy can be transferred from the air to the brine. The phenomena can be described as a partly short circuited system. The losses in the pipes going from the bottom to the roof are indicated with black arrows and the losses for the pipes going roof to the bottom is indicated with grey arrows. The losses in the system matches the difference in energy transfer rate between the Bottom HX and the Roof HX. Note that both diagrams have broken y-axis.

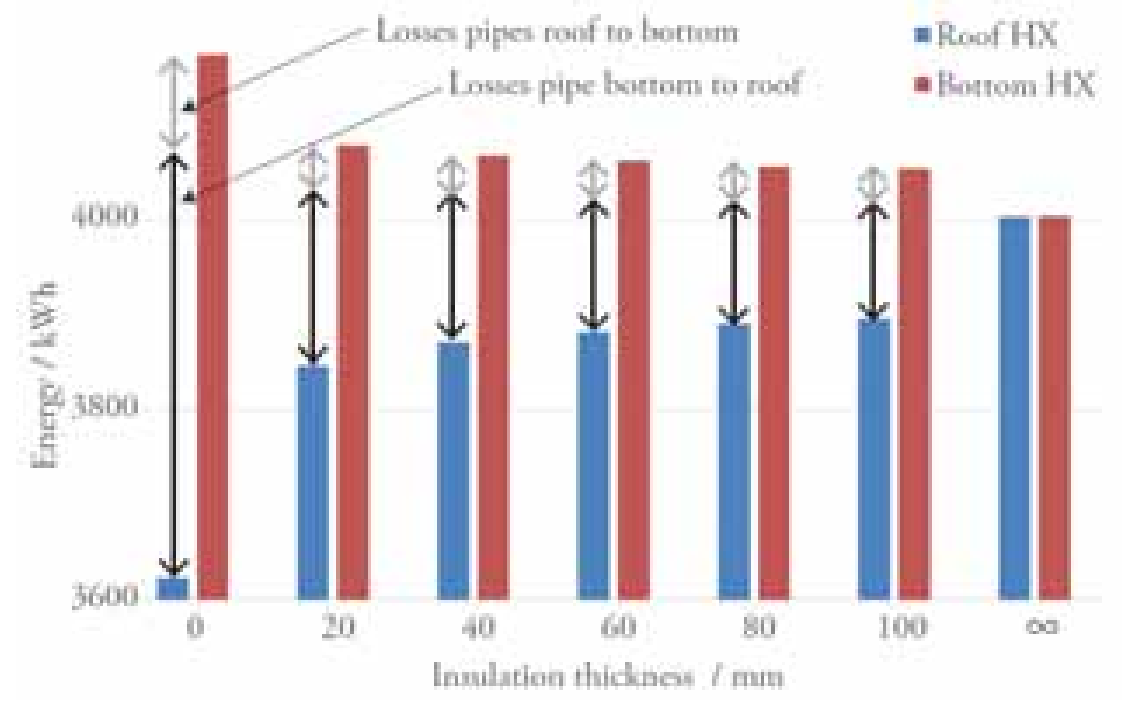

Fig. 3: Blue and red bars shows the heat transfer in the Roof HX (heat exchanger) and the Bottom HX. The black and the grey arrows indicate the thermal losses in the brine pipes. The black arrow is for the pipe going from the Bottom HX to the Roof HX and the grey arrow shows the losses related to the brine pipes going from the Roof HX to the Bottom HX. Note the broken y-axis.

Another consequence of the heat losses from the indoor air to the brine is that the heat exchanger at the bottom of the building will have slightly warmer incoming brine compared to a case with uninsulated pipes. The incoming air will therefore also be warmer. Simulations show that the incoming air is approximately $0.5^{\circ} \mathrm{C}$ higher for the case with uninsulated pipes compared to pipes without any heat losses.

\section{Conclusion}

Not insulating the pipes in a run-around heat recovery system will result in increased heating need. A typical one family house with a total of $40 \mathrm{~m}$ piping for the ventilation system will suffer from approximately 300 $\mathrm{kWh}$ higher energy need due to the pipe losses. However, insulating the pipes has the potential to lower the energy losses to approximately $50 \mathrm{kWh}$. It's also apparent that the losses from the pipe is heavily suppressed already by 20 to $40 \mathrm{~mm}$ insulation. Further insulation has limited impact.

Using uninsulated pipes will lead to a higher temperature for the incoming air due to heat losses from the indoor air to the brine. However, these losses only lead to a $0.5^{\circ} \mathrm{C}$ temperature rise for uninsulated pipes compared to pipes with no losses. This difference will not be significant for the performance of the ventilation system. A $1 \mathrm{~kW}_{\mathrm{p}} \mathrm{PV}$ module tilted in $40^{\circ}$ placed in Lund in the south of Sweden produces approximately 1 $000 \mathrm{kWh} /$ year. That means that a $250 \mathrm{~W}_{\mathrm{p}}$ module would produce approximately the same amount of electricity as the above discussed insulation saves for the ventilation system.

\section{Discussion}

Since the brine in the pipes can be considerably colder than the indoor temperature there is a large risk of having condensation on the pipes. This is not bad only for the energy performance. It can also cause humidity 
related problems where the pipes are placed. If the pipes are insulated there will be less humidity from the indoor air that condense on the pipes.

One of the main advantages with a run around heat recovery system for retrofitting of ventilation systems in old building is the fact that the pipes needed for this system is in most cases easier to install than ducts are in a traditional balanced mechanical ventilation system. This is not discussed in this article even though it is well worth to mention.

The total savings of insulating the pipes in the ventilation system approximately corresponds to the annual electricity production from a $250 \mathrm{~W}_{\mathrm{p}} \mathrm{PV}$ module. However, it should be taken into account that the electricity from the PV panels could be used to run a heat pump therefore producing more that the needed $250 \mathrm{kWh}$.

\section{Acknowledgement}

Thanks to Håkan Gustafsson at ISOVER for guidance regarding the program IsoDim.

\section{References}

BBR (2011), Swedish Building Code, Boverkets Byggregler, ”BBR 19, 6 Hygien” http://www.boverket.se/globalassets/vagledningar/kunskapsbanken/bbr/bbr-22/bbr-avsnitt-6 (accessed 201509-29)

Davidsson, H., Bernardo, R., Hellström, B., 2013a "Theoretical and Experimental Investigation of a Heat Exchanger Suitable for a Hybrid Ventilation System”, Buildings 3, 18-38

Davidsson, H., Bernardo, R., Hellström, B., 2013b "Hybrid Ventilation with Innovative Heat Recovery-A System Analysis", Buildings 3, 245-257

Hviid, C.H., Svendsen, S., 2011 "Analytical and experimental analysis of a low-pressure heat exchanger suitable for passive ventilation”, Energy and Buildings 43, 275-284

IsoDim, ISOVER, ISOVER IsoDim ${ }^{\circledR}$ version 3.07, http://www.isover.se/broschyrer+och+hj\%C3\%A4lpmedel/ber\%C3\%A4kningsprogram+teknisk+isolering (accessed 2015-09-29)

METEONORM. METEONORM 5.0 global meteorological database for solar energy and applied meteorology. Retrieved 2015-09-29, 2013, from http://www.meteotest.ch/en/

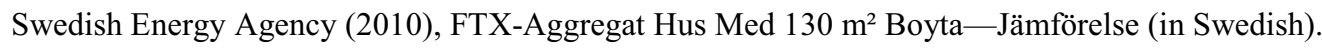
Available online:

http://www.energimyndigheten.se/Templates/Public/Pages/ProductGroupPageCompare.aspx?productGroupI $\underline{\mathrm{d}=69 \text { \&productCompareList }=412,413,414,415,416,417,418,419 \& \text { PageID }=5552}$ (accessed on 2015-09-29) 
